\title{
Perioperative mechanical circulatory support in children: An analysis of the Society of Thoracic Surgeons Congenital Heart Surgery Database
}

\author{
Christopher E. Mascio, MD, ${ }^{a}$ Erle H. Austin III, MD, ${ }^{a}$ Jeffrey P. Jacobs, MD, ${ }^{b}$ Marshall L. Jacobs, MD, \\ Amelia S. Wallace, BSPH, ${ }^{\mathrm{d}}$ Xia He, BS, MS, ${ }^{\mathrm{d}}$ and Sara K. Pasquali, MD
}

\begin{abstract}
Objectives: Analyses of mechanical circulatory support (MCS) in pediatric heart surgery have primarily focused on single-center outcomes or narrow applications. We describe the patterns of use, patient characteristics, and MCS-associated outcomes across a large multicenter cohort.
\end{abstract}

\begin{abstract}
Methods: Patients (aged $<18$ years) in the Society of Thoracic Surgeons (STS) Congenital Heart Surgery Database (2000-2010) were included. The characteristics and outcomes of those receiving postoperative MCS were described, and bayesian hierarchical models were used to examine variations in the adjusted MCS rates across institutions.
\end{abstract}

\begin{abstract}
Results: Of 96,596 operations ( 80 centers), MCS was used in 2.4\%. The MCS patients were younger (13 vs 195 days, $P<.0001)$ and more often had STS-defined preoperative risk factors $(57.2 \%$ vs $32.7 \%, P<.0001)$. The operations with the greatest MCS rates included the Norwood procedure (17\%) and complex biventricular repairs (arterial switch, ventricular septal defect, and arch repair [14\%]). More than one half of the MCS patients did not survive to hospital discharge $(53.2 \%$ vs $2.9 \%$ of non-MCS patients; $P<.0001)$. MCS-associated mortality was greatest for truncus arteriosus and Ross-Konno operations (both 71\%). The hospital-level MCS rates adjusted for patient characteristics and case mix varied by 15 -fold across institutions, with both high- and lowvolume hospitals having substantial variation in MCS rates.

Conclusions: Perioperative MCS use varied widely across centers. The MCS rates were greatest overall for the Norwood procedure and complex biventricular repairs. Although MCS can be a life-saving therapy, more than one half of MCS patients will not survive to hospital discharge, with mortality $>70 \%$ for some operations. Future studies aimed at better understanding the appropriate indications, optimal timing, and management of MCS could help to reduce the variation in MCS use across hospitals and improve outcomes. (J Thorac Cardiovasc Surg 2014;147:658-65)
\end{abstract}

Mechanical circulatory support (MCS) has been used perioperatively in the care of critically ill children with congenital heart disease and is often life-saving. Although several devices are being investigated, including those being

From the Department of Thoracic and Cardiovascular Surgery, ${ }^{a}$ University of Louisville, Louisville, Ky; Johns Hopkins Children's Heart Surgery, ${ }^{b}$ All Children's Hospital and Florida Hospital for Children, St Petersburg, Tampa, and Orlando, Fla; Department of Surgery, ${ }^{c}$ Johns Hopkins University School of Medicine, Baltimore, Md; Duke Clinical Research Institute, ${ }^{\mathrm{d}}$ Durham, NC; Department of Pediatrics, ${ }^{\mathrm{e}}$ University of Michigan C.S. Mott Children's Hospital, Ann Arbor, Mich.

Dr Pasquali has received support from the National Heart, Lung, and Blood Institute (grant K08HL103631)

Disclosures: Dr Jacobs is the Chair of the Society of Thoracic Surgeons Congenital Heart Surgery Database Task Force. All other authors have nothing to disclose with regard to commercial support.

Read at the 93rd Annual Meeting of The American Association for Thoracic Surgery, Minneapolis, Minnesota, May 4-8, 2013.

Received for publication May 5, 2013; revisions received Aug 29, 2013; accepted for publication Sept 30, 2013; available ahead of print Nov 18, 2013.

Address for reprints: Christopher E. Mascio, MD, Department of Thoracic and Cardiovascular Surgery, University of Louisville, 201 Abraham Flexner Way, Suite 1200, Louisville, KY 40202 (E-mail: cmascio@louisvilleheartsurgery.com).

$0022-5223 / \$ 36.00$

Copyright (c) 2014 by The American Association for Thoracic Surgery

http://dx.doi.org/10.1016/j.jtcvs.2013.09.075 evaluated currently in the National Institutes of Health in the Pumps for Kids, Infants, and Neonates (PumpKIN) trial, the most common form of pediatric MCS has been extracorporeal membrane oxygenation (ECMO). ECMO can be rapidly and simply initiated. It was first used in a pediatric patient in 1974 at Orange County Medical Center (Los Angeles, Calif), and Robert Bartlett, MD, first successfully supported a neonate with ECMO (to treat meconium aspiration). ${ }^{1}$ Since then, the application of ECMO has expanded to include cardiopulmonary support of patients with congenital heart disease. As the surgical repair of congenital heart disease has become increasingly complex, ECMO use has become more common. Reports of its use in this population have included bridging to heart transplantation, rescue cardiopulmonary resuscitation, and failure to wean from cardiopulmonary bypass. ${ }^{2-4}$ However, these reports have primarily included small cohorts, were most often from single institutions, and tended to be narrowly focused on a specific patient population. Currently, understanding is limited regarding the use and outcomes associated with ECMO after congenital heart surgery across institutions. 


\section{Abbreviations and Acronyms \\ $\mathrm{ECMO}=$ extracorporeal membrane oxygenation \\ ELSO $=$ Extracorporeal Life Support Organization \\ MCS = mechanical circulatory support \\ STS $=$ Society of Thoracic Surgeons}

The Society of Thoracic Surgeons (STS) Congenital Heart Surgery Database collects perioperative information on all patients at participating institutions undergoing pediatric and congenital heart surgery, including information regarding the use of perioperative MCS. Approximately $85 \%$ of all US pediatric heart surgery centers participate in this database, and, therefore, it is a valuable repository of information regarding the use of MCS in congenital heart surgery patients. ${ }^{5}$ The primary objective of the present study was to use the STS Congenital Heart Surgery Database to describe the patterns of use, patient characteristics, and outcomes associated with MCS across a large multicenter cohort.

\section{METHODS}

\section{Data Source}

The STS Congenital Heart Surgery Database contains operative, perioperative, and outcomes data on $>250,000$ patients who have undergone congenital heart surgery since 1998 and currently includes information from 105 participating hospitals. Data from all patients undergoing pediatric and congenital heart surgery at participating centers are entered into the database. Data quality and reliability are ensured through intrinsic verification of data and a formal process of site visits and data audits. ${ }^{6}$ The Duke Clinical Research Institute serves as the data warehouse and analytic center for all STS national databases. The Duke University institutional review board and STS Access and Publications Committee approved the present analysis.

\section{Patient Population}

For the present study, 1,32,854 cardiac operations (with or without cardiopulmonary bypass) performed on patients aged $<18$ years from 2000 to 2010 at 96 hospitals participating in the STS Congenital Heart Surgery Database were eligible for inclusion. A total of 16 centers with $>15 \%$ missing data on study variables were excluded. Although the STS DATABASE contains nearly complete data for the standard data fields required to calculate operative mortality, not all centers submit complete data for all variables, such as patient preoperative characteristics or postoperative complications. Therefore, it has been standard practice to exclude centers with data missing for key study variables to maximize data integrity and minimize missing data. ${ }^{7}$ From the remaining 80 centers, the patients with data missing for the study variables were also excluded, leaving a final study population of 96,596 patients.

\section{Data Collection}

The data collected from the STS Congenital Heart Surgery Database included demographic information, cardiac diagnoses, presence of a noncardiac/genetic abnormality, and the presence of any STS-defined preoperative risk factors. ${ }^{8}$ The operative data included information regarding the primary procedure of the index (first) cardiovascular operation of the admission, which was analyzed individually and also categorized using the STS-European Association for Cardiothoracic Surgery risk stratification system (category 1, lowest mortality risk; category 5, greatest mortality risk). ${ }^{9}$ This system was recently developed using empiric data from nearly 80,000 patients and includes a greater number of operations than other risk stratification systems. ${ }^{9}$ The number of previous cardiothoracic operations and cardiopulmonary bypass times were also collected. The use of both pre- and postoperative MCS (of any type) was collected. In the earlier years of data collection, detailed information regarding the specific type of MCS was not collected in the database; therefore, the present study analyzed MCS use in aggregate. In addition, detailed information regarding the timing of the initiation and duration of MCS is not currently collected in the database. The outcomes data included inhospital mortality and postoperative length of stay.

\section{Statistical Analysis}

The preoperative, operative, and outcomes data were described for the overall cohort and for the subgroups of patients undergoing the most common operations using standard summary statistics. The data were compared between those who received MCS and those who did not using the chisquare test or Wilcoxon rank sum test. Most of the analysis focused on postoperative MCS use, given the relative rarity of preoperative MCS use.

To examine the variation in postoperative MCS rates across hospitals, bayesian hierarchical models were used to calculate the adjusted postoperative MCS rates for each hospital. The models were adjusted for patient characteristics and case mix to account for any differences across hospitals, including patient age, gender, weight at surgery, the presence of any STSdefined preoperative risk factors or noncardiac/genetic abnormality, previous cardiothoracic surgery, the use of preoperative MCS, STS-European Association for Cardiothoracic Surgery category, and date of surgery. This method also accounted for the increased variability in outcomes from centers with a smaller sample size and shrinks the estimates form smaller centers toward the population average to provide more stable estimates. ${ }^{10}$ The distribution of adjusted MCS rates across hospitals was described and plotted against the hospital-average annual overall cardiac surgical volume. Finally, to further investigate the relationship between center volume and MSC rates, we also calculated the adjusted MCS rates across center volume categories $(<150,150-249,250-349$, and $\geq 350$ total cardiac cases annually) as follows: adjusted rate $=$ observed rate/predicted rate $\times$ sample average rate, where the predicted rates were from a marginal logistic model, including the aforementioned patient and operative factors. All analyses were performed using Statistical Analysis Systems, version 9.3 (SAS Institute, Inc, Cary, NC), and WinBUGS, version 1.4.3 (the Bayesian inference Using Gibbs Sampling project, Cambridge, UK). $P<.05$ was considered statistically significant.

\section{RESULTS}

A total of 96,596 congenital cardiac operations from 80 hospitals were included. The included hospitals were diverse geographically (44\% South, 24\% Midwest, $21 \%$ West, and $11 \%$ Northeast). The overall MCS rate was $2.8 \%$ $(\mathrm{n}=2750)$, including preoperatively $(0.5 \% ; n=463)$, postoperatively $(2.2 \% ; \mathrm{n}=2136)$, or both $(0.1 \% ; \mathrm{n}=151)$. Additional analysis focused on the group receiving any postoperative MCS $(\mathrm{n}=2287,2.4 \%)$. ECMO support accounted for $>95 \%$ of the instances of postoperative MCS.

\section{Study Population Characteristics}

The characteristics of the study cohort overall and those who received postoperative MCS and those who did not are listed in Table 1. The patients receiving postoperative MCS were younger, weighed less, and more often had an STSdefined preoperative risk factor than did the patients without 
TABLE 1. Patient characteristics, operative characteristics, and outcomes of study population

\begin{tabular}{|c|c|c|c|c|}
\hline \multirow[b]{2}{*}{ Characteristic } & \multirow[b]{2}{*}{ Overall $(n=96,596)$} & \multicolumn{2}{|c|}{ Postoperative MCS use } & \multirow[b]{2}{*}{$P$ value } \\
\hline & & Yes $(n=2287)$ & No $(n=94,309)$ & \\
\hline \multicolumn{5}{|l|}{ Patient } \\
\hline Age (d) & $189(28-1227)$ & $13(5-124)$ & $195(31-1259)$ & $<.0001$ \\
\hline Weight $(\mathrm{kg})$ & $6.3(3.5-14.2)$ & $3.4(2.9-5.1)$ & $6.4(3.6-14.4)$ & $<.0001$ \\
\hline White race & $47,605(49.3)$ & $1094(47.8)$ & $46,511(49.3)$ & $<.0001$ \\
\hline Male gender & $52,670(54.5)$ & $1262(55.2)$ & $51,408(54.5)$ & .004 \\
\hline Noncardiac abnormality & $29,464(30.5)$ & 677 (29.6) & $228,787(30.5)$ & .3 \\
\hline \multicolumn{5}{|c|}{ STS preoperative risk factors } \\
\hline Any & $32,115(33.3)$ & $1310(57.3)$ & $30,805(32.7)$ & $<.0001$ \\
\hline Mechanical ventilation & $15,303(15.8)$ & 837 (36.6) & $14,466(15.3)$ & $<.0001$ \\
\hline Arrhythmia & $2206(2.6)$ & $90(4.6)$ & $2116(2.6)$ & $<.0001$ \\
\hline Shock & $1727(1.8)$ & $170(7.4)$ & $1047(1.7)$ & $<.0001$ \\
\hline \multicolumn{5}{|l|}{ Operative } \\
\hline Previous CT operation & $26,939(27.9)$ & $458(20.0)$ & $26,481(28.1)$ & $<.0001$ \\
\hline \multicolumn{5}{|l|}{ STAT category } \\
\hline Low $(1-3)$ & $69,447(71.9)$ & $581(25.4)$ & $68,866(73.0)$ & $<.0001$ \\
\hline High (4-5) & $23,756(24.6)$ & $1653(72.3)$ & $22,103(23.4)$ & $<.0001$ \\
\hline CPB time (min) & $95(64-140)$ & $175(121-252)$ & $94(63-137)$ & $<.0001$ \\
\hline \multicolumn{5}{|l|}{ Outcomes } \\
\hline In-hospital mortality & $3940(4.1)$ & $1217(53.2)$ & 2723 (2.9) & $<.0001$ \\
\hline Length of stay (d) & $6(4-14)$ & $28(12-56)$ & $6(4-13)$ & $<.0001$ \\
\hline
\end{tabular}

Data presented as n (\%) or median (interquartile range) for continuous variables. MCS, Mechanical circulatory support; STS, Society of Thoracic Surgeons; STAT, Society of Thoracic Surgeons-European Association for Cardiothoracic Surgery; $C T$, cardiothoracic; $C P B$, cardiopulmonary bypass.

MCS. The patients receiving MCS were more likely to have received a preoperative shock $(7.4 \%$ vs $1.7 \%)$, to have preoperative arrhythmia $(4.6 \%$ vs $2.6 \%)$, and to have been mechanically ventilated $(36.6 \%$ vs $15.3 \%)$. No clinically meaningful differences were found in race/ethnicity, gender, or the proportion with a noncardiac/genetic abnormality in the MCS and non-MCS groups. The operative characteristics are also listed in Table 1. The MCS cohort was more likely to have undergone higher complexity operations involving longer cardiopulmonary bypass times.

\section{Overall Outcomes}

More than one half of those who received postoperative MCS did not survive to hospital discharge (Table 1). The in-hospital mortality was $53.2 \%$ compared with $2.9 \%$ for those who did not receive MCS $(P<.0001)$. As expected, the length of stay was prolonged for those who received MCS (median 28 vs 6 days; $P<.0001$; Table 1 ).

\section{Postoperative MCS Rates and Outcomes for the Most Common Operations}

Operations with $>100$ patients in the overall cohort were evaluated further. Those with the greatest postoperative MCS rates are listed in Table 2. The greatest rates of MCS were observed for the Norwood procedure (17.0\%) and for complex biventricular repairs including the arterial switch plus ventricular septal defect plus aortic arch repair operation $(14.0 \%)$, truncus arteriosus repair $(9.4 \%)$, and

TABLE 2. Operations with highest postoperative MCS rates and associated outcomes

\begin{tabular}{|c|c|c|c|c|c|c|}
\hline Operation & $\begin{array}{c}\text { Total } \\
\text { cases }(n)\end{array}$ & $\begin{array}{c}\text { MCS } \\
\text { rate }(\%)\end{array}$ & $\begin{array}{c}\text { Mortality with } \\
\text { MCS }(\%)\end{array}$ & $\begin{array}{c}\text { Mortality without } \\
\text { MCS (\%) }\end{array}$ & $\begin{array}{c}\text { Unadjusted OR } \\
\text { (MCS vs no MCS) }\end{array}$ & $P$ value \\
\hline Norwood procedure & 3272 & 17 & 57 & 13 & 8.7 & $<.0001$ \\
\hline $\mathrm{ASO}+\mathrm{VSD}+$ aortic arch repair & 139 & 14 & 40 & 3 & 19.2 & $<.0001$ \\
\hline Damus-Kaye-Stansel & 430 & 13 & 40 & 10 & 6.0 & $<.0001$ \\
\hline Truncus arteriosus repair & 689 & 9.4 & 71 & 5.5 & 42.0 & $<.0001$ \\
\hline Ross-Konno operation & 225 & 9.3 & 71 & 3.4 & 70.4 & $<.0001$ \\
\hline Unifocalization MAPCA & 466 & 8.4 & 41 & 8 & 8.0 & $<.0001$ \\
\hline TAPVC repair & 1850 & 8.2 & 59 & 7.4 & 18.1 & $<.0001$ \\
\hline $\mathrm{ASO}+\mathrm{VSD}$ & 855 & 7.5 & 53 & 3.2 & 34.7 & $<.0001$ \\
\hline ALCAPA repair & 397 & 7.3 & 14 & 1 & 19.5 & $<.0001$ \\
\hline
\end{tabular}

$M C S$, Mechanical circulatory support; $A S O$, arterial switch operation; $V S D$, ventricular septal defect; $M A P C A$, major aortopulmonary collateral artery; TAPVC, total anomalous pulmonary venous connection; $A L C A P A$, anomalous origin of coronary artery from pulmonary artery. 
the Ross-Konno procedure $(9.3 \%)$. Of all of the operations examined, postoperative MCS was associated with a greater risk of in-hospital mortality. This risk was greatest for the Ross-Konno procedure (mortality with MCS, $71 \%$; vs without MCS, 3.4\%; unadjusted odds ratio, 70.4; $P<.0001$ ) and truncus arteriosus repair (mortality with MCS, $71 \%$; vs without MCS, $5.5 \%$; unadjusted odds ratio, 42.0; $P<.0001)$.

The STS-defined "benchmark" operations of varying levels of complexity were also evaluated (Norwood procedure, truncus arteriosus repair, Fontan operation, arterial switch operation with or without ventricular septal defect repair, tetralogy of Fallot repair, complete atrioventricular canal repair, and ventricular septal defect repair), in addition to bidirectional Glenn/hemi-Fontan and atrial septal defect repair. The MCS rates and associated outcomes for these operations are displayed in Figure 1. As expected, the MCS rates increased with operation complexity. The MCS rate was $>5 \%$ for 3 of these 10 common operations. Postoperative MCS use was associated with greater inhospital mortality for all the benchmark operations.

\section{Variation in Postoperative MCS Rates Across Hospitals}

The variation in postoperative MCS rates across hospitals, adjusted for any differences in patient characteristics and case mix, was evaluated. As displayed in Figure 2, the median hospital level-adjusted MCS rate was $2.5 \%$ and varied from $0.6 \%$ to $9.3 \%$ across the 80 hospitals included in the present study (15-fold variation). We also examined the relationship of the overall cardiac surgical volume with the adjusted MCS rate. Although lower volume hospitals as a group had slightly greater MCS rates (Figure 3), the magnitude of this difference was relatively small, and a plot of each hospital's MCS rate versus total surgical volume did not demonstrate a clear overall relationship. Both high- and low-volume hospitals appeared to have substantial variation in MCS rates.

\section{DISCUSSION}

The present report, which used data from the STS Congenital Heart Surgery Database, focused on the patterns of use and outcomes associated with postoperative MCS. We found that the MCS rates were $>5 \%$ in nearly one third of the most common congenital cardiac operations performed and were greatest for neonates undergoing single ventricle palliative procedures and complex biventricular repairs. Despite being a potentially lifesaving therapy, more than one half of patients receiving MCS will not survive to hospital discharge, and the MCS-associated inhospital mortality for some operations has been $>70 \%$. The variation in MCS rates across hospitals was substantial, including both high- and low-volume centers.

MCS remains an emerging technology. Devices such as the intra-aortic balloon pump and ventricular assist pumps were initially developed primarily to meet the needs of adult patients, and the occasional application in the pediatric population was limited to relatively large patients. The emergence and refinement of ECMO support for respiratory failure in neonates and infants have led logically to the application of similar technology for cardiopulmonary support and to increasingly frequent use in patients with congenital heart disease. Although ECMO is still by far the most widely used form of MCS in pediatric cardiac surgery, it has recently been joined by alternative devices for univentricular or biventricular support.

The relatively young median age and lower weight for those receiving postoperative MCS was not surprising.

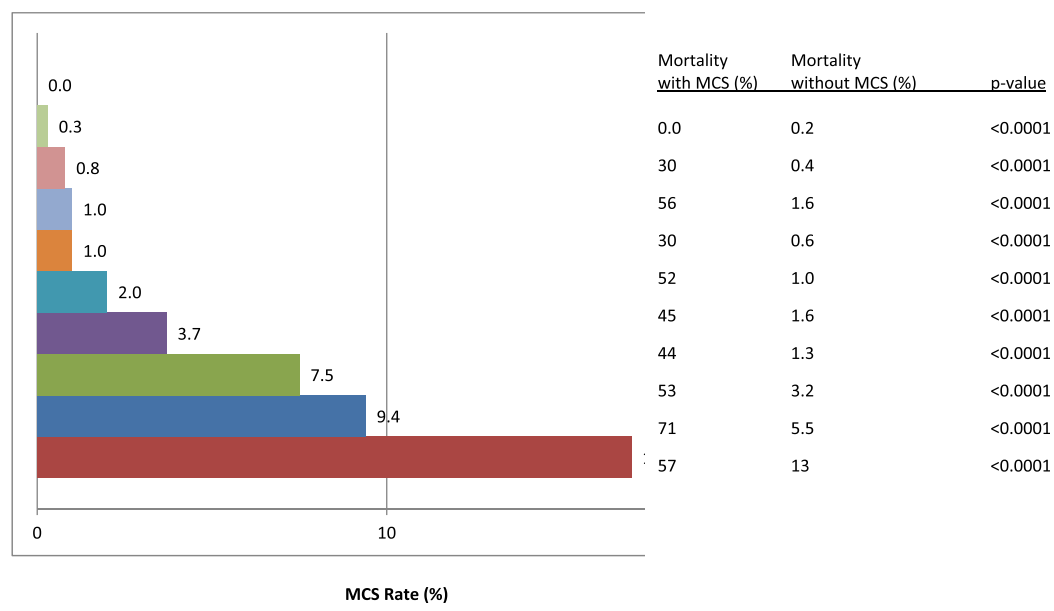

FIGURE 1. Postoperative mechanical circulatory support (MCS) rates for benchmark procedures and associated mortality. ASD, Atrial septal defect; VSD, ventricular septal defect; $B D G / H F$, bidirectional Glenn/hemi-Fontan; TOF, tetralogy of Fallot; $C A V C$, complete atrioventricular canal; $A S O$, arterial switch operation; ASO/VSD, arterial switch operation/ventricular septal defect; TA, truncus arteriosus; Nwood, Norwood. 


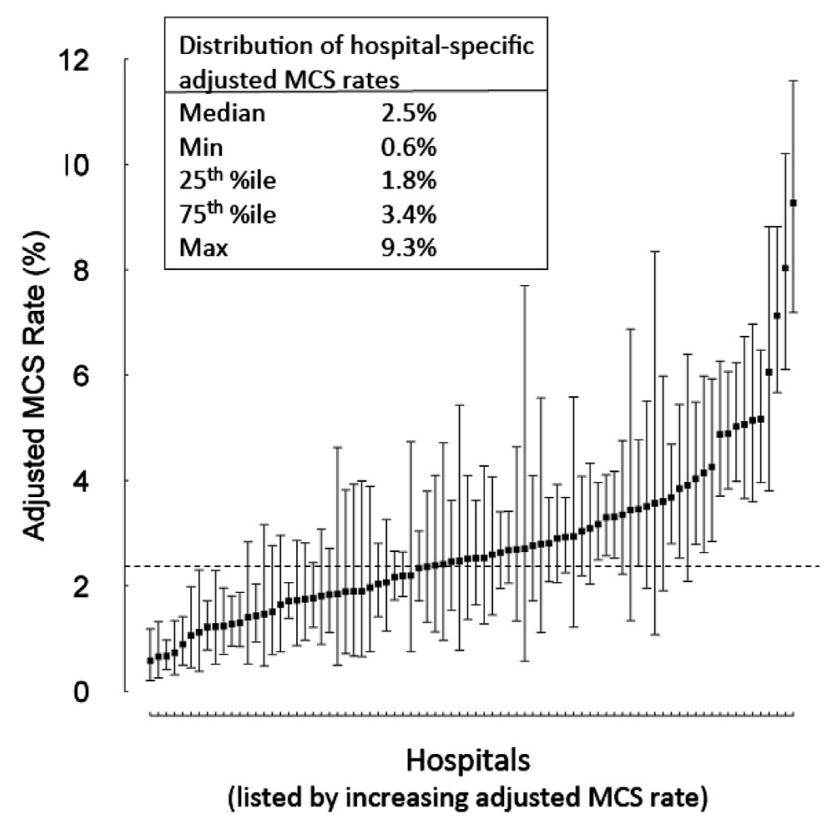

FIGURE 2. Variation in adjusted mechanical circulatory support (MCS) rates across hospitals. Adjusted postoperative MCS rates are listed for each hospital (black box represents adjusted estimate; lines, 95\% confidence intervals). The horizontal dotted line indicates the postoperative MCS rate in the overall cohort.

Improvements in perioperative care of the neonate with congenital heart disease has led to increased interest in early operative intervention in this population. ${ }^{11}$ Even in the setting of acceptable anatomic reconstruction, animal studies and clinical observation have suggested that the neonatal myocardium is uniquely susceptible to ischemiareperfusion injury. ${ }^{12,13}$ Published reports have also demonstrated that the presence of various preoperative risk factors increase the morbidity and mortality after complex neonatal repairs. ${ }^{14}$ Although survival has improved significantly in complex operations during the past 2 decades, these operations (including the Norwood procedure, arterial switch/aortic arch repair, and truncus/interrupted aortic arch repair) have been shown to have the greatest mortality risk of all congenital heart surgery operations. $^{15}$

The in-hospital mortality and length of stay we have reported were comparable and perhaps slightly lower than previously published data, including data from reports from the Extracorporeal Life Support Organization (ELSO) database. ${ }^{16,17}$ An ELSO study from 1989 to 2004 that included 5151 neonatal and pediatric cardiac cases reported that the in-hospital mortality for the neonatal and pediatric cardiac cohorts was $62 \%$ and $57 \%$, respectively. The subgroups examined included congenital defect, cardiac arrest, cardiogenic shock, cardiomyopathy, and myocarditis. The investigators also reported the incidence of mechanical and patient-related complications of

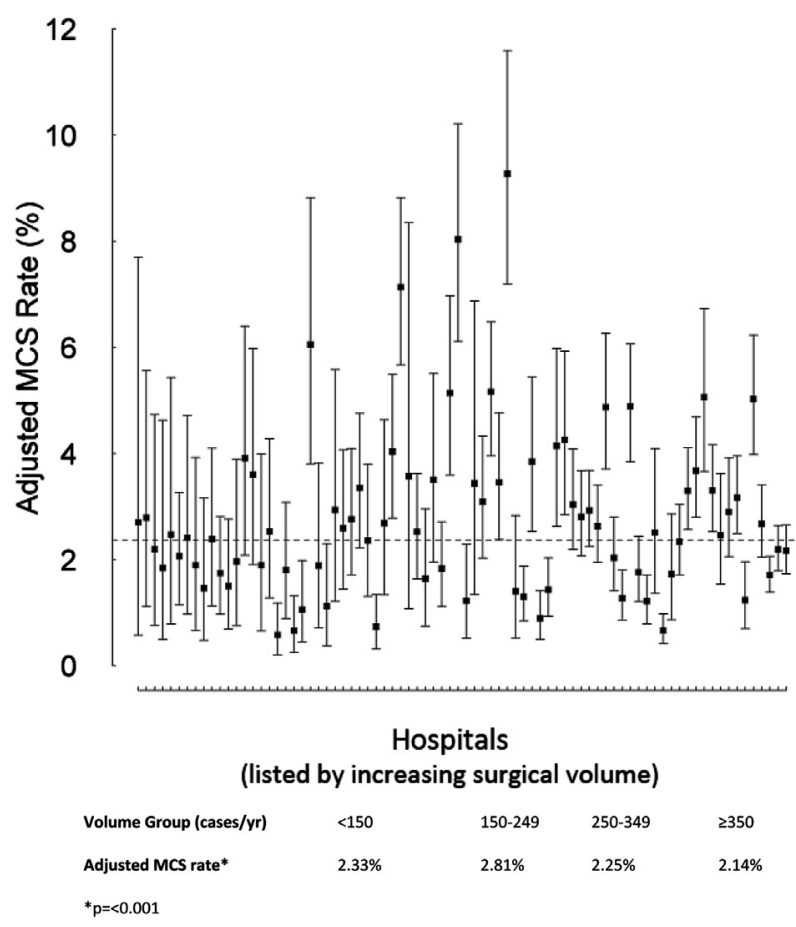

FIGURE 3. Relationship of adjusted mechanical circulatory support (MSC) rates with total surgical volume across hospitals. Adjusted postoperative MCS rates are listed for each hospital in order of increasing average annual total cardiac surgical volume (black box represents adjusted estimate; lines, $95 \%$ confidence intervals). The horizontal dotted line indicates the postoperative MCS rate in the overall cohort. The adjusted MCS rates in volume groups are also listed at the bottom of the plot.

ECMO in the cardiac population. The most common complication in each group was oxygenator failure $(7.2 \%)$ and surgical site bleeding $(31.0 \%)$. Unlike the present study, the ELSO study did not report on specific patient characteristics, preoperative risk factors, operative characteristics, individual congenital heart lesions, or interhospital variation.

The Norwood procedure had the greatest postoperative MCS rate in the present study. This operation can be 1 of the most challenging operations in congenital heart surgery, and it can be difficult to reliably reproduce technically perfect results. ${ }^{18}$ In addition, the resulting physiology is precarious and sensitive to minor changes in preload, afterload, and contractility. This has been highlighted by the $13 \%$ mortality in the present study in those Norwood patients who did not receive MCS. However, it is also important to note that the subgroup with the greatest mortality associated with MCS in the present study was not the single ventricle patients, but those patients undergoing biventricular repairs, including truncus arteriosus and Ross-Konno operations. Because no risk models have been established and validated for these relatively uncommon operations, which are sometimes performed on infants with severe physiologic embarrassment, we can only speculate 
regarding the specific reasons for the increased risk of mortality in patients receiving MCS after these procedures. Some common features include right ventriculotomy, the presence of many aortic suture lines that could exacerbate bleeding during MCS use, and the potential for coronary insufficiency with both repairs (coronary buttons and reimplantation usually for the Ross-Konno; abnormal coronary orifice locations possible in truncus arteriosus). What remains unclear is the relative contribution of patient factors and procedural factors to the need for, and ultimate salvage rate associated with, postoperative MCS. The balance of preoperative physiologic compromise, intraoperative myocardial ischemia and reperfusion, and the technical complexity of the operations (in particular, with respect to the restoration of adequate coronary artery anatomy and perfusion and the potential for residual defects and hemodynamic burdens) constitute a complex field of variables that might influence the need for MCS at separation from cardiopulmonary bypass or the likelihood of postoperative deterioration requiring resuscitation. It was not at all surprising, then, that operations such as the palliative Norwood procedure, repair of transposition with ventricular septal defect and arch obstruction, and the neonatal RossKonno procedure have been associated with the greatest rates of MCS. What remains to be determined is how best to take advantage of the available technology to maximize salvage of these patients. ${ }^{19,20}$

Although the mortality associated with MCS was high at $53 \%$, it is important to recognize that likely few to none of these patients would have been discharged alive without the use of MCS. Nonetheless, the wide variability in MCS rates we observed across centers, even after accounting for potential differences in case mix and patient characteristics, suggests ample room exists for improvement. Additional study is necessary to better understand the reasons underlying this variation, and whether the variation in MCS rates is associated with the known variation in mortality rates across hospitals. $^{21,22}$ Although the reasons for the wide variability in MCS rates across centers are not obvious, there are several potential explanations. The interval from the inception and rate of maturation of individual institutional ECMO (and other MCS) programs varied from center to center. Likewise, the threshold for instituting mechanical support reflects the judgment and experience of the individual surgeons and multidisciplinary critical care teams. In some centers, postoperative MCS might be limited to patients who cannot be weaned from cardiopulmonary bypass or who experience cardiac arrest in the intensive care unit. In others, mechanical support might be considered earlier and more frequently as a desirable alternative to escalating pharmacologic support. What is apparent is that MCS for postoperative support is used in the vast majority of centers, consistent with the Quality Measures for Congenital and Pediatric Cardiac
Surgery proposed by the STS, which include the availability of an institutional pediatric extracorporeal life support program. ${ }^{23}$

\section{Study Limitations}

The primary limitations of the present study were related to the nature of the STS database. Not all US centers participate in the STS database or submit complete data. Nonetheless, the present report represents the most broad evaluation of MCS use to date, including 80 US pediatric heart centers. In addition, in the earlier years of data collection, detailed information regarding the specific type of MCS was not collected in the database; therefore, we were limited to analyzing postoperative MCS use in aggregate. The addition of specific fields related to the use of ventricular assist devices in more recent versions of the data collection form will allow more detailed analyses of specific types of perioperative MCS in the future. The database also currently does not collect details regarding the indication for MCS support or other details related to MCS such as flow rates, specific duration of therapy, and MCS-related complications. Significant interhospital variation likely exists in many aspects of clinical care, including, but not limited to, anticoagulation, pump flow, vasoactive medication management, and weaning protocols. Future linkage of the STS Congenital Heart Surgery Database with the ELSO database could potentially address some of these limitations and allow analyses currently not possible using either data set alone. Finally, the database currently does not collect longer term follow-up data to evaluate the functional capacity and long-term survival of those patients receiving MCS.

\section{CONCLUSIONS}

Although MCS can be a life-saving therapy for children undergoing heart surgery, more than one half of children who receive MCS will not survive to hospital discharge, with MCS-associated mortality $>70 \%$ for certain operations. Although MCS was used most commonly in those undergoing single ventricle palliative procedures, MCS was also common for patients undergoing complex biventricular repairs, and the greatest mortality risk was associated with MCS in this latter group. MCS use varied widely across hospitals ( $\leq 15$-fold), even after accounting for any differences in case mix or patient characteristics, suggesting ample room for improvement. Future studies aimed at better understanding and standardizing indications for MCS, optimal timing, and MCS management might help to reduce the variation across hospitals and improve outcomes.

\section{References}

1. Wolfson PJ. The development and use of extracorporeal membrane oxygenation in neonates. Ann Thorac Surg. 2003;76:S2224-9.

2. Almond CS, Singh TP, Gauvreau K, Piercey GE, Fynn-Thompson F, Rycus PT, et al. Extracorporeal membrane oxygenation for bridge to heart transplantation among children in the United States: analysis of data from the Organ 
Procurement and Transplant Network and Extracorporeal Life Support Organization Registry. Circulation. 2011;123:2975-84.

3. Wolf MJ, Kanter KR, Kirshbom PM, Kogon BE, Wagoner SF. Extracorporeal cardiopulmonary resuscitation for pediatric cardiac patients. Ann Thorac Surg. 2012;94:874-9; discussion 879-80.

4. Delmo Walter EM, Alexi-Meskishvili V, Huebler M, Loforte A, Stiller B, Weng Y, et al. Extracorporeal membrane oxygenation for intraoperative cardiac support in children with congenital heart disease. Interact Cardiovasc Thorac Surg. 2010;10:753-8

5. Jacobs ML, Mavroudis C, Jacobs JP, Tchervenkov CI, Pelletier GJ. Report of the 2005 STS Congenital Heart Surgery Practice and Manpower Survey. Ann Thorac Surg. 2006;82:1152-8.

6. Clarke DR, Breen LS, Jacobs ML, Franklin RC, Tobota Z, Maruszewski B, et al. Verification of data in congenital cardiac surgery. Cardiol Young. 2008;18(Suppl 2):177-87.

7. Johnson JN, Jaggers J, Li S, O’Brien SM, Li JS, Jacobs JP, et al. Center variation and outcomes associated with delayed sternal closure following stage 1 palliation for hypoplastic left heart syndrome. J Thorac Cardiovasc Surg. 2010;139: 1205-10.

8. Society of Thoracic Surgeons. STS Database Full Specifications. Available at: http:// www.sts.org/sites/default/files/documents/pdf/CongenitalDataSpecificationsV3_0_ 20090904.pdf. Accessed February 21, 2012.

9. O'Brien SM, Clarke DR, Jacobs JP, Jacobs ML, Lacour-Gayet FG, Pizarro C, et al. An empirically based tool for analyzing mortality associated with congenital heart surgery. J Thorac Cardiovasc Surg. 2009;138:1139-53.

10. Kansy A, Tobota Z, Maruszewski P, Maruszewski B. Analysis of 14,843 neonatal congenital heart surgical procedures in the European Association for Cardiothoracic Surgery Congenital Database. Ann Thorac Surg. 2010;89:1255-9.

11. Dimick JB, Staiger DO, Birkmeyer JD. Ranking hospitals on surgical mortality: the importance of reliability adjustment. Health Serv Res. 2010;45(6 Pt 1): 1614-29.

12. Yue R, Hu H, Yiu KH, Luo T, Zhou Z, Xu L, et al. Lycopene protects against hypoxia/reoxygenation-induced apoptosis by preventing mitochondrial dysfunction in primary neonatal mouse cardiomyocytes. PLoS One. 2012;7:e50778.

13. Oka N, Wang L, Mi W, Zhu W, Honjo O, Caldarone CA. Cyclosporine A prevents apoptosis-related mitochondrial dysfunction after neonatal cardioplegic arrest. J Thorac Cardiovasc Surg. 2008;135:123-30.

14. Petrucci O, O’Brien SM, Jacobs ML, Jacobs JP, Manning PB, Eghtesady P. Risk factors for mortality and morbidity after the neonatal Blalock-Taussig shunt procedure. Ann Thorac Surg. 2011;92:642-51; discussion 651-2.

15. Okubo M, Benson LN, Nykanen D, Azakie A, Van Arsdell G, Coles J, et al. Outcomes of intraoperative device closure of muscular ventricular septal defects. Ann Thorac Surg. 2001;72:416-23.

16. Conrad SA, Rycus PT, Dalton H. Extracorporeal Life Support Registry Report 2004. ASAIO J. 2005;51:4-10.

17. Thourani VH, Kirshbom PM, Kanter KR, Simsic J, Kogon BE, Wagoner S, et al. Venoarterial extracorporeal membrane oxygenation (VA-ECMO) in pediatric cardiac support. Ann Thorac Surg. 2006;82:138-44; discussion 144-5.

18. Jacques F, Anand V, Hickey EJ, Kotani Y, Yadava M, Alghamdi A, et al. Medical errors: the performance gap in hypoplastic left heart syndrome and physiologic equivalents? J Thorac Cardiovasc Surg. 2013;145:1465-73; discussion 1473-5.

19. Baslaim G, Bashore J, Al-Malki F, Jamjoom A. Can the outcome of pediatric extracorporeal membrane oxygenation after cardiac surgery be predicted? Ann Thorac Cardiovasc Surg. 2006;12:21-7.

20. Woods RK, Pasquali SK, Jacobs ML, Austin EH, Jacobs JP, Krolikowski M, et al. Aortic valve replacement in neonates and infants: an analysis of the Society of Thoracic Surgeons Congenital Heart Surgery Database. J Thorac Cardiovasc Surg. 2012;144:1084-9.

21. Jacobs JP, O'Brien SM, Pasquali SK, Jacobs ML, Lacour-Gayet FG, Tchervenkov CI, et al. Variation in outcomes for risk-stratified pediatric cardiac surgical operations: an analysis of the STS Congenital Heart Surgery Database. Ann Thorac Surg. 2012;94:564-71; discussion 571-2.

22. Pasquali SK, He X, Jacobs JP, Jacobs ML, O’Brien SM, Gaynor JW. Evaluation of failure to rescue as a quality metric in pediatric heart surgery: an analysis of the STS Congenital Heart Surgery Database. Ann Thorac Surg. 2012;94:573-9; discussion 579-80.

23. Jacobs JP, Jacobs ML, Austin EH, Mavroudis C, Pasquali SK, Lacour-Gayet FG, et al. Quality measures for congenital and pediatric cardiac surgery. World $J$ Pediatr Congenit Heart Surg. 2012;3:32-47.

\section{Discussion}

Dr James Tweddell (Milwaukee, Wis). I would like to thank The American Association for Thoracic Surgery (AATS) for asking me to discuss this report. Chris, that was really a terrific presentation. You and your colleagues have explored the STS Congenital Heart Surgery Database for information on mechanical support among patients undergoing congenital heart surgery. Among almost 97,000 operations, the rate of MCS was $2.8 \%$, or 2750 cases. Of these 2750 patients, $17 \%$ received support preoperatively, $78 \%$ postoperatively, and $5 \%$ were fortunate enough to receive both preoperative and postoperative circulatory support. More than $95 \%$ of the patients were supported using ECMO; thus, we can really consider this a study of perioperative ECMO support.

Not surprisingly, the patients receiving MCS were younger, smaller, and more likely to have the preoperative risk factors of shock, in particular, mechanical ventilation and arrhythmias, and were more likely to require more complex procedures.

Just to be clear, to be included in the present study, there must have been an operation for congenital heart disease. Thus, patients admitted with acute myocarditis or dilated cardiomyopathy or receiving mechanical support as a bridge to recovery or transplantation would not have been included, is that correct?

Dr Mascio. That is correct.

Dr Tweddell. In addition, as you said, we do not have data on the indications for mechanical support such as inotrope score or any surrogates or measures of cardiac output or the use of cardiopulmonary resuscitation (CPR) at the time mechanical support was initiated.

Dr Mascio. Correct. The database did not track the inotrope score, measures of cardiac output, or the use of CPR during the study period (2000-2010).

Dr Tweddell. What was most dramatic to me was the plot of MCS use versus center volume. Naively, perhaps, I would have anticipated that larger volume centers would have used MCS less than would lower volume centers. The center variation was tremendous. This really illuminates the dramatic differences in practice patterns among centers. If you have seen 1 congenital heart surgery program, you have seen 1 congenital heart surgery program.

Did you explore any of the variations in practice patterns? Could you tell us whether a difference existed in the complexity-adjusted survival rates of MCS between those programs using MCS frequently and those using it very little?

Dr Mascio. We compared the MCS rate with the volume but did not examine survival at high versus low use centers.

Dr Tweddell. Was there a difference in survival between the high- and low-volume centers with MCS?

Dr Mascio. We do not know from the present study. A slight difference was present in the rate of mechanical support, but it was likely not clinically significant.

Dr Tweddell. You stated in your report, which was very wellwritten, that you studied the regional differences in the United States-northeast, south, west, et cetera. Did you see any differences or any consistency in the MCS used in the different regions?

Dr Mascio. We examined the location, but not the regional rate of use of MCS, of the 80 included centers. 
Dr Tweddell. Well, overall, the mortality was $>50 \%$ and certainly MCS in the perioperative setting is expensive and highly morbid. Clearly, we need some additional information on the indications for MCS. The next few questions really concern how we should proceed next.

Would you recommend that we add some data fields to the STS database in the future? Keeping in mind the substantial burden of the number of fields we already have.

Dr Mascio. Yes, I would. In fact, in the newest STS database form they have already added fields, including the type of assist device, the indication for initiation, and the reason for termination of support. Starting this summer, that form will be used and that information will be tracked.

Dr Tweddell. You also mentioned the ELSO database. Do you think there is an opportunity to go back with these data and the ELSO registry, such as Sara Pasquali has done for antifibrinolytics, to determine whether we can at least tease out who was receiving CPR at ECMO initiation?

Dr Mascio. I think so, because those 2 databases follow different data points. The ELSO database definitely has an extracorporeal CPR group that they follow and they also follow postoperative complications after ECMO. So I think using both databases can certainly provide us with some data that each one individually could not.

Dr Tweddell. Do you think it would be worthwhile trying to put together some sort of survey of North American centers to identify the indications for MCS? We could then match the indications with outcomes and potentially identify the best practices?

Dr Mascio. Yes, absolutely - and not just for indications, but for management also. For example, for anticoagulation management, some centers use anti-Xa levels, some centers use the activated clotting time, some centers use the partial thromboplastin time, and some use a combination of all of those.

Dr Tweddell. That was an excellent presentation. Just as with all very good reports, you have identified more questions for us to answer in the future. Thank you.

Dr Mascio. Thank you very much.

Dr V. Mohan Reddy (Stanford, Calif). Chris, I have 1 question for you. In your analysis, considering ECMO and the length of ECMO, was there any duration of ECMO beyond which it was futile and was discontinued?

Dr Mascio. The STS database during the 2000 to 2010 period did not follow that; thus, we do not know the reason for the initiation and/ or termination or the duration of support. We just know the patients had undergone an index operation that was followed by MCS.

Dr Reddy. Thus, obviously, if it was just a pure myocardial failure and the patient is receiving ECMO for that, I would suspect that beyond a certain period the myocardium is unlikely to recover.

Dr Mascio. From our findings, we could not really state that after 48 or 72 hours, or any duration for that matter, that ECMO should be discontinued. The end point we considered was in-hospital mortality.

Dr Reddy. I think it would be worthwhile data to gather from any database, because it would be important to know that beyond a certain period it is not worth continuing it.
Dr Mascio. I agree.

Dr Christian Pizarro (Wilmington, Del). Very nice presentation. Do you have any data that can help us understand why was it that although the Norwood patients tended to be supported more often, some of those complex ventricular repairs had the highest mortality? Also, if not, could you elaborate from what you know how that could be explained?

Dr Mascio. From the present study, no. Others have reported truncus arteriosus repair and Ross-Konno operation as very high-risk operations. In the present study, Norwood mortality, even without mechanical support, was $13 \%$. The present study cannot explain why mechanical support for some biventricular repairs was associated with very high mortality.

Dr Carl L. Backer (Chicago, Ill). Chris, congratulations on a terrific study. As Dr Tweddell said, this review might have opened up more questions than answers. However, it is important and eyeopening to realize that there is a $57 \%$ mortality rate for putting a patient on ECMO after a Norwood procedure. Many centers now experience external pressures on cost containment and I believe that at some point, we might not be able to afford this therapy. It will be up to us to decide who is going to receive ECMO and who is not, from both a quality of life standpoint and a careful use of resources standpoint. We are going to have to somehow figure this out.

I agree that the idea of a survey proposed by Dr Tweddell is a very good one. Perhaps we could then develop consensus-based guidelines for using ECMO in the postoperative period. At some centers, no patient dies without first receiving ECMO. We need to decide whether this is in the best interest of the patient and the family. Consider a neonate with heterotaxy, total veins, pulmonary atresia, an unbalanced atrioventricular septal defect, and severe postoperative atrioventricular valve insufficiency. Perhaps that patient should not be receiving ECMO automatically for severe ventricular dysfunction after the operation. It will be incumbent on us as a group to determine this before external forces tell us when we can and cannot use ECMO. Do you have any thoughts on this socioeconomic issue?

Dr Mascio. I think that doing a survey is a very good idea. When we were writing our report, we were careful to use the phrase "receiving mechanical support" and not "requiring mechanical support." Because, as you said, it is different for every institution. Some institutions use ECMO for all patients, and some would take a patient such as you just described and not offer MCS.

Dr V. Mohan Reddy (Stanford, Calif). I think it might probably be worthwhile to have a task force similar to the American Heart Association task force that can develop guidelines for ECMO, when to start and whom to start and when to discontinue. It might be something the Association might consider.

Further Discussion by James Tweddell, MD

Dr Tweddell (Milwaukee, Wis). The last comment, the rate of ECMO support for the Norwood procedure was $17 \%$ in the present study, which goes back many years; $15 \%$ in the Single Ventricle Reconstruction trial. Thus, I think it is pretty much within the range of what many institutions experience. 